\title{
Can Bio-fertilizers Produced from Agricultural Residues Be Used In Hydroponics as an Alternative to Synthetic Fertilizers?
}

\author{
Maria Olímpia Oliveira Rezende* and Leandro Antunes Mendes
}

São Carlos Institute of Chemistry, University of São Paulo, Brazil

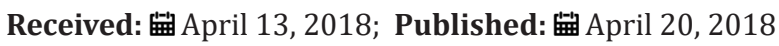

*Corresponding author: Maria Olímpia Oliveira Rezende, São Carlos Institute of Chemistry, University of São Paulo, Brazil

\begin{abstract}
Biofertilizer is the liquid effluent obtained from aerobic or anaerobic decomposition of organic matter in the presence of water, or to be more specific, it is the remaining matter left from the decomposition of organic compounds containing both single celled or multi cellular organisms (bacteria, yeasts, filamentous fungi and algae) and the metabolites they generate. Some of the statistics relating to Brazil's increasing dependence on the use of pesticides in agriculture are quite concerning. For example, in the last 15 years, within the state of Ceará, incidences of rare types of cancer arose to 38\% above the national average. Likewise, the sale of agrochemicals in Brazil grew 190\% over the last 10 years, which is more than twice the world average. Of the 50 most commonly used pesticides in the Brazil, 15 of them are actually banned in Europe. According to the last Brazilian Health Regulatory Agency (Anvisa) survey, agrochemicals have been found in $67 \%$ of the foods analyzed ( $25 \%$ of which were banned). In view of this alarming reality, a change of attitude is not just necessary, it is mandatory. We need to change our philosophy regarding agricultural management on a national level, one that promotes viable agricultural methodologies to produce crops and livestock, which result in a more healthful humanity and a balanced, sustainable environment.
\end{abstract}

\section{Introduction}

In the last two decades, the production of food, which requires less synthetic inputs, has attracted the attention of both research and industry. A productive and relatively inexpensive process is the use of biofertilizers prepared from the aerobic or anaerobic digestion of organic materials as a substitute for mineral-based fertilizers, in order to contribute to reduced consumption of the natural reserves of nutrients on the planet. Our goal is to reduce our nation's dependence on agrochemicals including pesticides and synthetic, inorganic and mineral-based fertilizers. In keeping with this thinking, we have cultivated lettuces (Lactuca sativa L.) inside a greenhouse using a self-contained hydroponic system, and have successfully utilized reused agricultural matter as a substantive growth promoting solution without the need for the addition of agrochemicals (pesticides or fertilizers). The herbaceous lettuce species we chose is one of the most cultivated vegetables in the country and is of great economic importance, generating quick profitability to the producer due to its short cycle from seeding to harvest [1]. We also selected this crop as it exhibits a wide adaptability to diverse climatic conditions and is one of the most produced crops via hydroponics and thus can be grown year round.

\section{Case Report}

For the production of our specific biofertilizer, poultry litter, orange bagasse and cattle manure were combined and mixed in several concentrations. The $\mathrm{pH}$, electric conductivity, salt concentration, lactic acid content, total organic carbon, nutrients (N, P, K, Ca, Mg, Cu, Fe, Mn and $\mathrm{Zn}$ ), organic matter content, humic substances, and health quality attributes (total thermotolerant coliforms, E. coli, etc.) were assessed for each of the biofertilizer blends. Phenol, carbohydrate and amino acid concentrations were evaluated as well. Phenols are derived from plant lignins, which are cross-linked phenolic polymers and are important for plant structure and rigidity. Carbohydrates are important for the soil organic matter cycle, and are easily hydrolyzed by microorganisms - representing $10-30 \%$ of the organic carbon in the soil. Amino acids 
are an essential nitrogen source and are generated by the aerobic decomposition process due to the hydrolysis of various proteins. Amino acids are also very beneficial throughout the plant life cycle and are essential to numerous physiological and biochemical processes (protein synthesis, phytohormone formation, water balance regulation, ion-chelation required for plant sustenance, etc.). Urease activity was also evaluated in order to evaluate the dynamics of agricultural material transformation in biofertilizers.

After 60 days of decomposition, the biofertilizers were filtered using a tow and stored in barrels. For application in hydroponics, the biofertilizers were diluted until the electrical conductivity remained around $2500 \mu \mathrm{S} \mathrm{cm}-1$. The most successful results were obtained using a mixture of poultry and cattle manure in equal parts as $20 \%$ $(\mathrm{v} / \mathrm{v})$ of the total composition ( $80 \%$ water). It can be concluded, based upon the quantitative analysis and characterization we conducted for all of the biofertilizer formulations we produced, are all in accord with the Ministry of Agriculture, Livestock and Supply, specifications, which requires determination of the properties of all potential commercial products. The biometric results we generated for the lettuce we grew under hydroponic cultivation show that use of biofertilizers contributed positively to the productivity of the crop. When the poultry and cattle biofertilizer, which showed the best agronomic potential, was applied to the crop, lettuces were produced which exhibited the best biometric results in terms of agronomic potential [2].

After 30 days of cultivation (see illustration) lettuces grew to $28 \mathrm{~cm}$ (12 inches) of height and fresh shoot mass reached $(24.26 \pm 2.87) \mathrm{cm}$ and $(150.70 \pm 9.94) \mathrm{g}$, respectively (Figure 1). Recycling of organic matter has the advantage of reducing costs when compared to synthetic fertilizers, it maintains the Organic Matter (OM) cycle, and is a supplementary source of nutrients. It is noteworthy that the poultry and cattle manure mixture did not produce coliforms on the lettuces when cultivated under specified conditions.

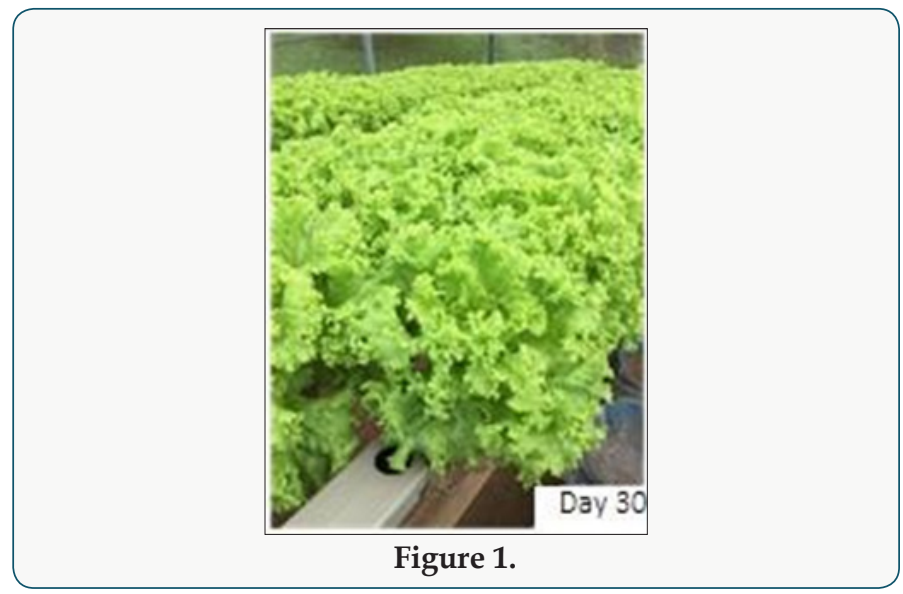

\section{Conclusion}

However, at this time, these potential products would have to be further analyzed, tested and characterized to determine expiration dates, and currently there is no regulation or laws, which can be applied to the production of biofertilizers. Achieving these goals will require continued research and movement within the national legislative arena.

\section{References}

1. Mendes LA, Barione PP, Atoloye IA, Landgraf MD, Rezende MOO (2017) From agricultural residues to biofertilizers: preparation and characterization for use in hydroponics. American Open Chemistry Journal. 3(1): 1-14.

2. Paulo R, Dores Silva, Maria D, Landgraf, Maria OO Rezende (2018) Humification process in different kinds of organic residue by composting and vermicomposting: have microbioreactors really accelerated the process?. Environ Sci Pollut Res p. 1-9.

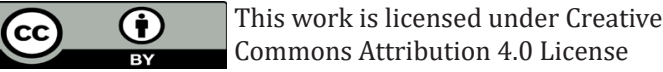

To Submit Your Article Click Here:

Submit Article

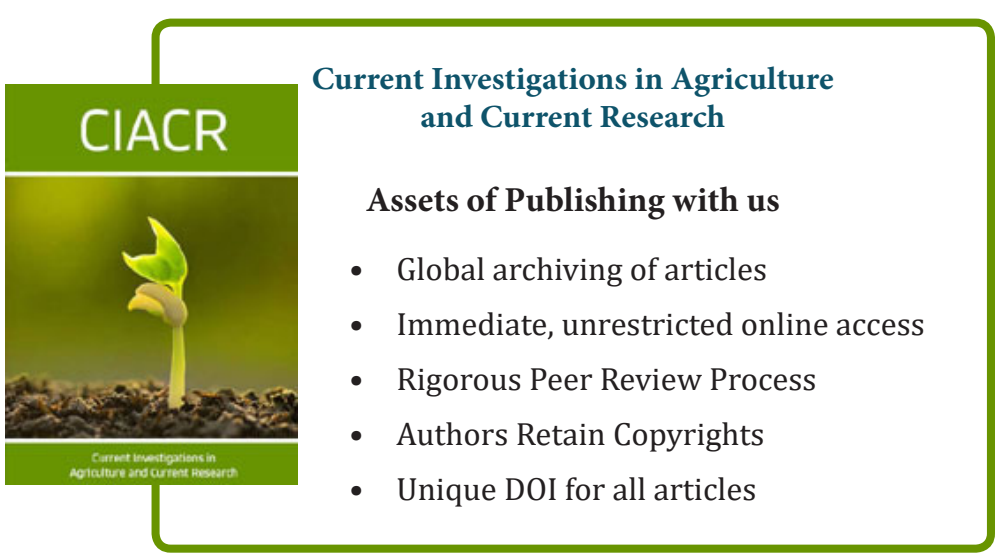

Citation: Maria O O R, Leandro A M. Can Bio-fertilizers Produced from Agricultural Residues Be Used In Hydroponics as an Alternative to Synthetic 